\title{
HYPOTHESIS
}

\section{Evidence that mammalian sex ratios at birth are partially controlled by parental hormone levels around the time of conception}

\author{
William H James \\ The Galton Laboratory, University College London, Wolfson House, 4 Stephenson Way, London NW 12 HE, UK \\ (Correspondence should be addressed to W H James; Email: whjames@waitrose.com)
}

\begin{abstract}
An attempt is made to summarize the evidence that the offspring sex ratios (proportions male at birth) of mammals (including man) are causally related to the hormone levels of both parents around the time of conception. Almost all of the cited studies were reported by non-endocrinologists. This being so, it would seem desirable to have comments of
\end{abstract}

endocrinologists on this topic. The purpose of this article is to elicit such comment. Readers are requested to read the accompanying editorial (Clark \& Davis 2008) to gain a better perspective of this hypothesis article.

Journal of Endocrinology (2008) 198, 3-15

\section{Introduction}

The human sex ratio (proportion of males) at birth is strikingly stable, seldom varying significantly from values that lie roughly between 0.505 and 0.520 (James 1987). Thus, in almost all human populations, there is a slight excess of males at birth. The cause of this excess has not been established and will not be further discussed here. Over the last century, a huge quantity of epidemiological data has been accumulated on human sex ratios. It has become clear that there is a variation in sex ratio shown by a number of such demographic variables available in birth certificates and hospital registries (e.g. birth order, maternal age, social class, smoking, marital status of mother, race, wartime, etc). However, these variations are so small that they give little reasonable prospect of suggesting the causes of the variation and they will not be treated here. However, more recently it has been suggested that some selected adverse prior parental experiences (such as illness, occupational and chemical exposures) are associated with subsequent human sex ratios that are substantially and significantly different from expected population values. It is appropriate to seek explanations for these differences.

It had been conventionally believed that

(a) there are equal numbers of $\mathrm{X}$ and $\mathrm{Y}$ in mammalian sperms,

(b) $\mathrm{X}$ and $\mathrm{Y}$ stood equal chances of achieving conception,

(c) therefore equal numbers of male and female zygotes were formed, and that (d) therefore any variation of sex ratio at birth is due to sexselective spontaneous fetal wastage.

Evidence has been put forward against these conclusions. It may readily be conceded that some sex ratio variation is due to sex-selective foetal and embryonic wastage (as, e.g. with glucose (Gutierrez-Adan 2001) and psychological stress during pregnancy (Catalano et al. 2006)). However, some sex ratio variation is almost certainly present at the time of formation of the zygotes (James 2006a, Cameron \& Linklater 2007) and so the question arises: what is the cause of this variation in sex ratio the time of formation of the zygotes?

It is possible that some environmental agents directly affect the ratio of men's X- and Y-bearing sperm: this has been suggested by Robbins et al. (2007) as a cause of the low offspring sex ratio reported in men exposed to boron (James 1999, Chang et al. 2006). However parental hormone concentrations around the time of conception may play a role by predisposing to the production of one sex or the other, for example, high levels of gonadotrophins to the production of daughters (James 1980). And in their review of nonhuman mammalian sex ratios, Clutton-Brock \& Lason (1986) wrote: '.. in view of... the apparent lack of genetic variance in the sex ratio, a hormonal mechanism mediated by environmental factors operating either at conception or during the individual's development appears to be the most likely explanation of sex ratio variation'. Later it was suggested that high paternal concentrations of testosterone are associated with the production of sons (James 1986). These 
suggestions were augmented with proposals that high levels of oestrogens were associated with sons and progesterones with daughters (James 1996, 2004a). The idea can be encapsulated in the proposal that offspring sex ratio correlates positively with $R$, where $R$ is a function of the form

$(T+E) /(G+P)$

where T, E, G and $P$ are the sex-standardized concentrations of testosterone, oestrogen, gonadotrophins and progesterone of both parents. The relationship between offspring sex ratio and parental hormone levels may be mediated by glycerylphosphorylcholine in the male and its diesterase in the female tract (James 1997). As far as I know, this latter hypothesis has not been tested.

Although this endocrinological speculation is in the public domain, it has, in a sense, gone on behind the backs of endocrinologists. Data on the relationships between mammalian offspring sex ratio and parental hormone levels have been published in a large variety of journals (within the fields of, e.g. evolutionary biology, environmental medicine and animal husbandry) by researchers with different interests and approaches, most of whom (like me) are not qualified in endocrinology. Yet even if the hypothesis was substantially correct, it would need developing by experts in the field of endocrinology. For instance, if hormone concentrations are involved, then hormone sensitivity/insensitivity, agonists/ antagonists and hormone receptors are also probably involved.

If the hypothesis was substantially correct, it would have ramifications in a wide range of medical specialties (toxicology, teratology, radiation medicine, neurology, psychiatry, oncology, dermatology, rheumatology, occupational medicine, virology and parasitology as well as obstetrics and gynaecology; James 2001a). In particular, it may throw light on the present concern over endocrine disruptors (James 2006b). Lastly, if the hypothesis was correct, it may help solve a recurrent problem in endocrinology: namely the assessment of past hormone profiles of people now diagnosed with illness. Sex ratios may be potential surrogates for hormone profiles that existed many years in the past, namely at the time when children were conceived. The point is that if people with a given pathological diagnosis produce children with an unusual sex ratio before the diagnosis, then ex hypothesi, the corresponding hormone profile is a potential cause of the pathology. Furthermore, if the unusual sex ratio (or another one) were to apply only to children conceived after disease onset, one may suspect that the disease (or its treatment) has hormonal consequences.

The purpose of this note is to persuade endocrinologists that mammalian sex ratios merit their attention. Here, as noted above, variables will be ignored which only have minor variation with sex ratio. Moreover (with some exceptions e.g. dioxin), topics will be ignored if they are the subject of conflicting reports.

It is hoped that the wealth of data reviewed here will provoke endocrinologists into commenting on, and experimentalists into testing, the hypothesis. This is so because - even if it were substantially correct - only after such comment and testing will the hypothesis stand any chance of becoming accepted.

The data to be reviewed will be considered under the following categories:

(A) observational studies of human beings and

(B) observational and experimental studies on non-human mammals.

\section{Observational studies on human beings}

\section{Time of insemination within the menstrual cycle}

It is suggested that offspring sex ratio (proportion of males) is associated with the time of insemination within the fruitful cycle. The length of the fertile window (that time within the cycle in which insemination may result in conception) is of the order of 5 days or more (Schiphorst et al. 1985, Keulers et al. 2007). Apparently, the regression of sex ratio on time of insemination (vis-à-vis time of ovulation) is $U$ shaped. In other words, if the insemination occurs early or late in the fertile window, the resulting offspring is more likely to be male: if insemination occurs in the middle, it is more likely to be female. The author performed a meta-analysis on 10 independent data sets on this point and the resultant Mantel-Haenszel test statistic was significant at the 0.005 level (James 2000a). Similar phenomena have been reported in other species viz white-tailed deer (Verme \& Ozoga 1981), Barbary macaque (Paul \& Kuester 1987), golden hamster (Pratt et al. 1987), Norway rat (Hedricks \& McClintock 1990), mouse (Jimenez et al. 2003) and pig (Brooks et al. 1991). It is suggested that hormonal changes across the cycle are responsible for the observed variation of offspring sex ratio. In the human being, the luteal hormone surge in the middle of the cycle is ex hypothesi responsible for the excess of females reportedly conceived at that time.

\section{Finger length ratios}

There is good evidence that $R$, the ratio of the lengths of the second $(2 D)$ and fourth $(4 D)$ fingers (where $R=2 D / 4 D$ ) correlates negatively with men's testosterone concentrations (Manning et al. 1998, Manning 2002). According to the author's hypothesis, it was predicted that men's $R$ values should correlate negatively with their offspring sex ratios (James 2001b). The prediction was confirmed by Manning et al. (2002).

\section{Direct treatment with hormones}

\section{Women}

Hormonal induction of ovulation

The sex ratio of children following the induction of ovulation with gonadotrophins or clomiphene is low (James 1985a). This result is highly significant $\left(P<10^{-6}\right.$, tested against a contemporary expected live birth sex ratio of 0.514 in the USA). It is not totally due to any association between sex ratio and female sub-fertility: this may be inferred from the fact that 
the sex ratio of artificial insemination offspring is also significantly lower if ovulation is hormonally induced rather than natural (James 1985b). I suggest that the excess of females among the offspring following hormonally induced ovulation is due to gonadotrophins used in the induction of ovulation (or secreted as a consequence of treatment by other agents).

\section{Women exposed to diethylstilbestrol (DES) in utero}

Wise et al. (2007) reported a raised offspring sex ratio in women who themselves were exposed to DES in utero. Those exposed earliest in gestation and having the highest doses had the highest odds of a male birth. There can be no reasonable doubt that postnatally these 'DES-Daughters' have higher levels of testosterone than controls (Giusti et al. 1995). It is suggested that this testosterone is responsible for the high sex ratio.

\section{Men}

Sas \& Szollosi (1980) administered gonadotrophins to one group of sub-fertile men and methyltestosterone to another. Both groups of men subsequently sired highly significant excess of sons $(P<0 \cdot 00005$ and $P<0.005$ respectively) which could lead to the implication that the excess to the testosterone group was directly due to the hormone. Subfertile men treated with mesterolone, a synthetic androgen of lower potency than methyltestosterone, have also been reported to sire a significant excess of sons (James 1990).

The gonadotrophin sample of Sas \& Szollosi (1980) was treated with 1500 I.U. intramuscularly twice a week. When gonadotrophin is administered to men in this quantity, it clears rather rapidly from the system, peaking at $6 \mathrm{~h}$ and being no longer detectable at $48 \mathrm{~h}$ (Padron et al. 1980). However, the administration of such doses of gonadotrophin to men results in sustained high levels of both testosterone and oestradiol (Matsumoto et al. 1983). So it seems reasonable to suggest that the high sex ratio of offspring of Sas \& Szollosi's gonadotrophin-treated patients was due to the fathers' high levels of testosterone and oestradiol and relatively low levels of gonadotrophin. At any rate it seems that the sex ratios of offspring of Sas \& Szollosi's patients were not caused by a tendency of (untreated) sub-fertile men to sire boys. This is because untreated sub-fertile men tend to produce girls (perhaps because of their low testosterone levels; James 1990). I suggest that the failure of Jacobsen et al. (2000a) to find this depended - as they suggest - on a heterogeneity across sub-fertile men in regard to offspring sex ratios. Such heterogeneity would be expected to arise as a consequence of pooling untreated men (who produce an excess of daughters) with men who had been treated with androgens (who produce an excess of sons).

\section{Pathological conditions}

\section{Cancers}

Pre-menopausal breast cancer is reportedly associated with a significantly high offspring sex ratio (James 2006c). This may be provisionally ascribed, ex hypothesi, to the high levels of oestrogenic activity that are thought to be causally associated with the disease. Several other cancers are reportedly associated with significantly low offspring sex ratios (non-Hodgkin's lymphoma, testicular cancer and post-menopausal breast cancer). Table 1 gives references to these reports and to papers confirming that the hormone profiles of patients conform with this hypothesis.

\section{Infectious conditions}

\section{Toxoplasma gondii infection}

This parasite is common in human beings with between 20 and $60 \%$ of the populations of most countries being infected (Flegr et al. 2005). Kankova et al. (2007a) reported that (in contrast to uninfected controls) infected women are more likely to produce sons $(P=0 \cdot 001)$, and that the offspring sex ratio (proportion of males) increases with the concentration of anti-Toxoplasma antibodies in Toxoplasma-positive mothers $(P=0.001)$. This group of workers also reported similar findings on experimentally infected female mice (Kankova et al. 2007b). Comments on this experiment will be made in a later section ( $T$. gondii).

These human data may be explained as follows. A number of reports have given grounds for supposing that the testosterone (T) concentrations of infected people are high.

Flegr et al. (2005) reported that infected men and women (as contrasted with uninfected controls) have lower values of

Table 1 References substantiating that the given cancers are associated with (a) low offspring sex ratios and (b) hormone profiles ex hypothesi responsible for those sex ratios

\section{Cancer}

Non-Hodgkin's lymphoma Testicular cancer

Post-menopausal breast Cancer

\section{Low sex ratio}

\section{Hormone profile}

Olsson (1984)

Olsson \& Brandt (1982)

Moller (1998)

Jacobsen et al. (2000b)

Gundy et al. (2004)

James (2006C)
Petersen et al. (1999)

Collins et al. (2005)

Beral et al. (2003)

The author gratefully acknowledges Dr M Zwitter (Ljubljana, Slovenia) for information on confirmatory data on the offspring sex ratio of patients with non-Hodgkin's lymphoma (NHL; 96 boys and 106 girls born to female patients before diagnosis). 
Manning's $R$ (where $R=2 D / 4 D, 2 D$ is the length of the second digit and $4 D$ the length of the fourth digit). As noted above (in section Finger length ratios), $R$ reportedly correlates negatively with circulating $T$ levels (Manning et al. 1998, Manning 2002). Flegr et al. (2005) also reported that $R$ correlated negatively with levels of anti-Toxoplasma antibodies in Toxoplasma-free subjects. Lastly, Hodlova et al. (2007) reported that female students judged that men with latent toxoplasmosis appeared more dominant $(P=0 \cdot 009)$ and masculine $(P=0 \cdot 052)$ than uninfected controls.

Hodlova et al. (2007) inferred that infected men have higher $T$ levels than uninfected controls. Flegr et al. (2005) concluded that their 'results suggest that some of the observed differences between infected and non-infected subjects may have existed before infection'. The author suggests that both conclusions are correct and that there is lower natural resistance to toxoplasmosis infection in subjects with high testosterone levels.

The point may be further tested as follows:

(a) The $\mathrm{T}$ levels of infected men and women should be directly assayed.

(b) Experimentally infected animals should be given anti-androgenic treatment: it would be interesting to know whether this ameliorates the effects of infection.

(c) The offspring sex ratio of infected men should be examined.

(d) The dynamics between Toxoplasma and testosterone are not established.

Evidence has been presented to show that subjects with high $\mathrm{T}$ levels are more vulnerable to infection, but since women react to stress by increased secretion of adrenal androgens (Christiansen 2004), one may suspect that the infection may also initially cause a rise in adrenal androgens in women. This needs investigation in longitudinal studies. If I am correct, then the $\mathrm{T}$ levels of infected women (and of experimentally infected female mice) are initially high (partially as a response to the stress of infection). Furthermore, these high $T$ levels gradually diminish (perhaps as the subject becomes habituated to the stress).

\section{Hepatitis B virus $(H B V)$}

During their work on HBV, Blumberg and his colleagues repeatedly found that HBV carriers (of both sexes) produce statistically significant excesses of sons. This work was summarized by Chahnazarian et al. (1988) and the result confirmed by Oster (2005). These authors were unable to explain their findings, and indeed, the result has remained a major unsolved problem in hepatitis $\mathrm{B}$ research (Blumberg 2006).

However, Yuan et al. (1995) found that in healthy men, the geometric mean $\mathrm{T}$ was $21 \%$ higher in $\mathrm{HBsAg}^{+}$individuals than in $\mathrm{HBsAG}^{-}$individuals $(P=0 \cdot 0006$, two-way analysis). So it is suggested that hepatitis $\mathrm{B}$ carriers have an excess of sons because they have high $\mathrm{T}$ levels. This may explain some of the other curious forms of variation of hepatitis B by sex (Blumberg 2006) and may indicate endocrine control of rates of viral transmission and/or replication. This line of reasoning is supported by the (otherwise unexplained) highly significant excess of brothers among the siblings of hepatitis B carriers (Mazzur \& Watson 1974). Testosterone concentrations have strong genetic determinants (Harris et al. 1998).

If the above argument was correct, then hepatitis B infection might be treated with anti-androgens. It is noteworthy that an analogous suggestion has recently been made in respect of HIV/AIDS. It has been shown that oestrogen protects against vaginal transmission of simian immunodeficiency virus (SIV) in ovariectomized Rhesus monkeys (Smith et al. 2000) and that progesterone implants enhance SIV vaginal transmission and early viral load in Rhesus monkeys (Marx et al. 1996). On the basis of this (and other) evidence, it was proposed that oestrogen and progesterone may alter women's susceptibility to HIV infection and that oestrogen treatment might accordingly ameliorate or protect against this condition in women (Short 2006).

\section{Cytomegalovirus (CMV)}

Women who are seropositive for CMV reportedly bear a significant excess of daughters (Piazze et al. 1999, Shields et al. 2002). Oestrogen has a generally suppressive effect on CMV replication (Speir et al. 2000). Therefore, oestrogen concentrations may be assumed to be low in CMV-positive women: hence ex hypothesi the low offspring sex ratio of CMV-positive women.

\section{Pathological obstetric conditions}

Unusual offspring sex ratios are associated with a number of obstetric conditions. Highly significant male excesses have been reported in placenta praevia, the fatty liver of pregnancy and (some forms of) toxaemia (James 1995a); dermatoses of pregnancy (James 2000b); highly significant female excesses in placenta accreta and extrauterine pregnancy (James 1995a) and hyperemesis gravidarum (HG; James 2001c). Foetal sex is not thought to cause any of these conditions, and it is suggested that the abnormal sex ratios are caused by unusual maternal hormone profiles around the time of conception, and that these same abnormal hormone profiles persist and later are partially responsible for the pathology (James 1995a). The suggestion was speculative at the time but has gained strength in the interim. Notes are given here on some of these pathologies and their associated sex ratios.

\section{Placenta praevia and extrauterine pregnancy}

The author adduced further evidence that placenta praevia is associated with male births (James 2001d). The hypothesized mechanism underlying the biased sex ratios associated with these two forms of pathology is as follows. The ovum is normally fertilized at the upper end of the fallopian tube. It is helped on its journey to the uterus by smooth muscle contractions of the tube, and it has been shown that these 
contractions are positively associated with oestrogen concentrations (Jansen 1984) and negatively associated with progesterone concentrations (e.g. Paltieli et al. 2000). So if the oestrogen/progesterone ratio is below optimum (and thus ex hypothesi associated with female conceptions) these contractions may be presumed to be insufficient to discharge the ovum into the uterus before it 'hatches' from the zona. Under these conditions, one may expect nidation in the tube itself and an ectopic pregnancy.

In contrast, in cases of placenta praevia, one may suspect an undue degree of hormonally induced tubal motility. In such cases, the fertilized ovum would be discharged into the uterus some days before it was due to 'hatch' and nidate. Under these circumstances, one would expect an excess of nidations in the vicinity of the cervix as a consequence of either random movement within the uterus or any slow escape of fluid from the uterus through the cervix.

In short, it is suggested that placenta praevia is due to high oestrogen/progesterone ratios (ex hypothesi associated with male conceptions) and that (some) ectopic pregnancies are caused by low ratios. Explanations are available for both these phenomena and for the unusual sex ratios associated with each. It is not claimed that anomalous degrees of tubal and myometrial motility or ciliary action are the only cause of either condition. The hypothesis could be tested by examining the extent to which hormone concentrations control such motility.

\section{Hyperemesis gravidarum}

Looking at data from 11 samples it is concluded that the sex ratio associated with HG is significantly below population live birth sex ratios (James 2001c). It has been reported that cases have high gonadotrophin levels (Hsu \& Witter 1993, Askling et al. 1999). Moreover, Depue et al. (1987) cited epidemiological data and direct endocrinological data to support the hypothesis that this condition may be caused by 'an extremely rapid rise in oestradiol in early pregnancy'. So there are grounds for suspecting that women destined to suffer HG have a low oestrogen/gonadotrophin ratio around the time of conception. The point stands in need of confirmation.

\section{Pathological conditions known or thought to arise in utero}

It is well established that most forms of congenital malformation affect one sex more than the other (Arena \& Smith 1978, Lubinsky 1997). For instance, polydactyly is more common in boys and anencephaly in girls. The explanations for most of these sex ratio biases are not established, so it is suggested that some sex-predisposing maternal hormone profiles may also (partially) cause specific congenital anomalies. The point may be tested by examining the sex ratio of unaffected siblings of probands with a particular sex-related malformation. If the sex ratio of these siblings is biased in the same direction as that of the probands, then the hypothesis is supported in respect of that malformation. And if the sex ratio is not so biased, the hypothesis is impugned. Such a line of reasoning would explain the unusual (and otherwise unexplained) sibling sex ratios of probands with polydactyly (James 1998a,b), transposition of the great arteries (James 1999), oral clefts (James 2000c) and pyloric stenosis (James $2004 b$ ). It may also explain the highly significant male excess in the siblings of probands diagnosed with some male-biased neurodevelopmental disorders (e.g. autism spectrum and attention deficit hyperactivity disorder; James 2008).

\section{The HLA-B15 gene}

This gene is reportedly more common in men with rheumatoid arthritis than in healthy controls (Cutolo \& Accardo 1991). Ollier et al. (1989) found that men who carried the HLA-B15 gene had significantly lower testosterone levels than other men. So Astolfi et al. (2001) tested a prediction based on the present hypothesis, namely that men carrying HLA-B15 should sire a high proportion of daughters. The prediction was confirmed and these authors wrote: 'These results suggest an effect of HLA-B15 on the secondary sex ratio mediated by a low testosterone level'.

\section{Pathological chemical exposures and the possibility of detecting endocrine disruptors}

It has been known for many years that national sex ratios at birth change slowly but significantly up and down across time (Gini 1955). Some of these movements may have been due to changing methods of reporting. Moreover, increases of sex ratio have sometimes been ascribed to reductions in rates of spontaneous abortion and regarded as evidence of an increasingly healthy population. But though these movements of national sex ratios at birth have been shown to be statistically significant, their causes have not been established. Those in the 19 th century and early 20th century occurred before a huge variety of pesticides and other chemical compounds were introduced. These movements may also have been due to industrial pollution (mediated ex hypothesi by endocrine disruption) or they may have been the consequence of genetic stabilizing mechanisms (Bodmer \& Edwards 1960). These qualifications are mentioned here for the following reason.

During the 1960s, 1970s and 1980s, sex ratios at birth declined in many (though not all) developed countries. It was known that paternal exposures to some specified chemicals (e.g. dibromochloropropane (DBCP) and other pesticides) caused (or at least were associated with) the production of a significant excess of daughters (e.g. Potashnik \& Yanai-Inbar 1987), so some people interpreted these falling sex ratios as evidence of deleterious environmental chemical agents. The argument is inconclusive because we do not know - and are unlikely to know until Gini's (1955) data have been explained - how the sex ratios might have moved in the absence of environmental pollution.

Nevertheless there are circumstances under which sex ratios may be used to detect endocrine disruptors: these will now be described.

There are grounds for supposing that the hormone levels of both fathers and mothers are involved in the sexes of their children (James 1996, 2004). Moreover, the endocrine 
responses of men and women to some noxious stimuli are thought to be not just different, but opposite. For instance, Christiansen (2004) cited evidence that the endocrine responses of men and women to stress are opposite: men experience a lowering of testicular androgens and women an increase in adrenal androgens. And one might suspect opposite endocrine responses of men and women to the current ubiquitous exposure to weak environmental oestrogens. These may be suspected of raising women's oestrogen levels and lowering men's testosterone levels. If these were correct, then ex hypothesi if both parents were exposed, the effects on sex ratio may be counterbalanced and go undetected. So when using sex ratios to test for endocrine disruption, it is necessary in principle to examine the offspring sex ratios of all four categories of matings of exposed and unexposed mothers and fathers. In the absence of such provision, an overall unchanged sex ratio may mask opposing effects in mothers and fathers. So sex ratio may not be a useful criterion of endocrine disruption where, for instance, chemical spillages into water sources or the atmosphere have occurred and where, therefore, both parents are likely to have been exposed. This has been illustrated in reportedly opposite trends in offspring sex ratio in response to maternal and paternal exposure to dioxin, DDT, polychlorinated biphenyls and lead. There follow brief surveys of the effects of selected chemical exposures where the exposure status of both parents was known.

\section{Dioxin (TCDD) and dioxin-like chemicals}

TCDD is one of a group of highly potent environmental pollutants. It induces a broad spectrum of biological responses including the disruption of normal hormone signalling pathways (Mandal 2005). It is a ubiquitous contaminant, originating from many sources (e.g. emissions from incineration sources, effluents and solid waste from pulp and paper processing, metal reclamation, petroleum refining, wood preservation and the production of specified chlorinated chemicals; Orban et al. 1994). For these reasons, it may be seen as a prototypical endocrine disruptor and has become the focus for much research. On the basis of the present hypothesis and the finding of a low testosterone/gonadotrophin ratio in men exposed to dioxin (Egeland et al. 1994), it was predicted that these men would sire an excess of daughters (James 1995b). Mocarelli et al. $(1996,2000)$ reported on births following the Seveso explosion (which released large quantities of dioxin into the atmosphere). These data seemed to confirm the prediction, but since then, other workers have reported both raised and lowered offspring sex ratios (see James 2006b, Table 2). In that note, the author gave grounds for suggesting that this heterogeneity may have been the consequence of contamination of dioxin with congeners with androgenic, oestrogenic or anti-oestrogenic properties. Mocarelli et al. (2000) were explicit that pure dioxin (but not a range of associated chemicals) was released at Seveso. Figa-Talamanca et al. (2003) examined the sex ratios at birth in the municipalities surrounding Seveso in the years following the explosion: these authors found a reduction only in the following 8 years $(1977-84)$ and they found that the reduction occurred only in the two municipalities with the highest levels of contamination. Moreover, recent experimental pre-mating administration of dioxin to male mice (Ishihara et al. 2007) and guinea pigs (Hwang et al. 2004) was reportedly followed by significantly lowered offspring sex ratios. So provisionally one may conclude, following Mocarelli, that male exposure to dioxin causes subsequent births of excess daughters.

\section{The organochlorine pesticide DDT}

Cocco et al. (2005) reported on DDT applicators involved in an anti-malarial campaign in Sardinia in 1946-50. The offspring sex ratio of these men decreased significantly by their tertile of cumulative DDT exposure. Moreover, exposure to DDT reportedly lowers testosterone levels in men (Martin et al. 2002) and male rats (Rhouma et al. 2001). Thus, these human data are accommodated by the presented hypothesis.

Evidence on the effects of prior maternal chemical exposures on offspring sex ratio is not abundant. So the recent paper of Khanjani \& Sim (2006) is important. Khanjani (private communication to me dated July 2006) reported that their most heavily contaminated women produced 32 boys and 13 girls $\left(\chi^{2}=7 \cdot 0, P<0 \cdot 01\right.$, tested against an expected live birth sex ratio of 0.513 in Australia). Apparently, DDT does not raise women's oestrogen levels (Perry et al. 2006), but organochlorine pesticides have been shown to act as oestrogen receptor agonists (Hodges et al. 2000). So it seems reasonable to propose that this sort of mechanism is responsible for the excess boys produced by exposed women. At any rate, the data on DDT seem to present evidence that a pollutant may have opposite effects on exposed men and women, judging by their offspring sex ratios.

\section{The nematocide dibromo chloropropane (DBCP)}

Potashnik \& Yanai-Inbar (1987) reported that men exposed to DBCP thereafter sired statistically significant excesses of daughters. These workers had conducted more than one study, and reported that the later work confirmed their original result. It had originally been reported that DBCP lowers men's sperm counts (Whorton et al. 1977), and for this reason, to the author's knowledge it was then banned in many countries, no further data have been published on its effect on offspring sex ratios. It has also been reported that exposure to DBCP causes increases in men's luteinizing hormone (LH) and folliclestimulating hormone levels, while leaving their testosterone levels unchanged (Whorton et al. 1979). The author suggests that this hormone profile is responsible for the female excess among the offspring of these men.

\section{Fungicides}

In some ways, the studies of Garry et al. (2002a,b, 2003) are unique. Not only did these workers replicate their earlier finding that male fungicide applicators sired a significant excess of daughters, but also the men whose hormones were assayed 
were the same subjects whose offspring sex ratios were reported. These authors concluded that fungicide exposure determines the sex of offspring. The author suggests that this is correct, the effect being mediated by the variation of testosterone levels later reported by this team (Garry et al. 2003).

\section{Adverse occupational exposures}

The author has cited evidence that four different classes of male occupational exposure are associated both with significantly low offspring sex ratios and significantly low paternal testosterone levels. These are: a) pilot of high-performance aircraft and astronaut, b) non-ionizing radiation, c) professional driver and d) professional diver (James 2006b). Of these four categories, only the last two will be elaborated on here.

\section{Professional driver}

Noting the evidence that professional drivers have poor sperm quality, and the evidence that lead lowers male testosterone levels, the author speculated that - if his hypothesis were correct - then professional drivers should sire an excess of daughters (James 1992). This prediction was confirmed first by Dickinson \& Parker (1994), who found a significant excess of daughters born to professional drivers, and second by Simonsen et al. (2006), who reported a significant dose-related decline in sex ratio with paternal blood lead level.

\section{Professional diver}

The only two sets of data (known to the author) on offspring sex ratios of professional divers are both strikingly low. Rockert (1977) reported 20 sons and 40 daughters born to deep sea divers in the Swedish Royal Navy, and Lyster (1982) reported 45 sons and 85 daughters born to Australian abalone divers. These two sex ratios are significantly lower than comparable national live birth sex ratios $(P=0.005$ and $P<0.0002$ respectively).

Though the author has no information on the medical status of the Swedish divers, Lyster himself reported on the flabby, unhealthy appearance of the Australian divers, and his comment was later amplified by expert authority: Edmonds \& Hayward (1987) wrote: 'The Australian abalone divers were interesting because of their extremely provocative diving procedures, the high prevalence of occupational diseases of diving, and the alleged presence of a punch-drunk syndrome ...' Meanwhile the extensive literature on the harmful effects of recreational (McQueen et al. 1994) and professional (Leplow et al. 2001, Ross et al. 2007) diving - even in the absence of accidents and decompression illness - is worth noting. These harmful effects may at least be suspected of being caused by or associated with endocrine change. Rockert et al. (1978) reported that the testosterone levels of rats exposed to a hyperbaric environment of air were significantly reduced; and Rockert \& Haglid (1983) reported that divers' testosterone levels decrease after diving.
Psychological and sociological variables

\section{Personality: dominance and the Trivers-Willard hypothesis}

During the past three decades, theoretical biologists have explored the notion of adaptive variation of sex ratio at birth. This would occur, when, by skewing the sex ratio of their offspring, parents increased their expected number of grandchildren. Theorists have devised several models embodying such adaptive variation. The most influential of these was described by Trivers \& Willard (1973; henceforth TW). Basically their idea was that under specifiable circumstances, there would be reproductive advantage if females were to skew their offspring sex ratio in one direction or the other. The circumstances were as follows:

(a) males have a higher variance of reproductive success than females,

(b) offspring inherit their mothers' 'condition' and

(c) 'condition' is positively associated with reproductive success.

Under these circumstances, females would have more grandchildren if mothers in good 'condition' were to have more sons and if mothers in poor 'condition' were to have more daughters. The above three circumstances are fulfilled in many species, including man. For the purpose of testing TW, dominance rank has frequently been used as a surrogate for 'condition'. It is noteworthy that dominant women reportedly produce a statistically significant excess of sons (Grant 1994) and have high testosterone levels (Grant \& France 2001). However, though the TW paper has been cited more than 1000 times, tests of the hypothesis in some taxa (e.g. primates) have been successful in about only $50 \%$ of (roughly 100) attempts (James 2006d). For this reason (among others), the author suggested, in that note, that parental hormones are not only responsible for adaptive variation of sex ratio, but also for constraints (processes which conflict with the adaptive processes) on that variation. In particular, it seems that high levels of testosterone in women may be associated with some forms of suboptimal health and (contrary to TW) the production of sons.

\section{Domiciliary arrangements}

The author noted the evidence that in human polygynous societies, where co-wives live together (in harems) they tend to produce an excess of sons: in contrast, where each co-wife resides in her own dwelling (and each is visited by the husband in turn), they tend to produce an excess of daughters (James 1995c). Perret (1990) reported a similar result after mating female mouse lemurs that were either previously isolated or grouped with other females. Perret (1986) had noted that, in that species, hormone levels throughout the ovarian cycle are strongly modified by the presence of other females. This association is mediated by urinary olfactory cues (Perret 1996). Perret \& Colaz (1997) strongly suggested that the sex ratio bias exists at conception. One may conclude that maternal 
endocrine variation is associated (presumably causally) with offspring sex ratio in this species.

\section{Observational and experimental studies on non-human mammals}

The sexes of the mother's own adjacent litter-mates in gerbils and mice

It was evident that the intrauterine position of rodents was associated with their subsequent adult hormone levels, females adjacent to two males (2M females) being more androgenized than females adjacent to two females (0M females). The author proposed an experiment to test whether (as predicted) the sex ratio of offspring of $0 \mathrm{M}$ females differs from that of $2 \mathrm{M}$ females (James 1989). The prediction was confirmed by Clark et al. (1993) who found that the sex ratio of offspring of OM female gerbils is significantly lower than that of $2 \mathrm{M}$ females. The authors make the point that $2 \mathrm{M}$ females from litters that contain a majority of females produced a significantly greater percentage of sons than $0 \mathrm{M}$ females from litters that contained a majority of males. This suggests that intrauterine position (and thus hormone levels) is responsible rather than maternal or foetal genotype.

Clark \& Galef (1994) also report a significantly higher sex ratio of offspring of caesarean-delivered pregnant $2 \mathrm{M}$ dams than that of offspring of caesarean-delivered $0 \mathrm{M}$ dams (thus eliminating the possibility that sex-related maternal cannibalism was responsible for their original result). Lastly Vandenbergh \& Huggett (1994) reported highly significant evidence for such a phenomenon in the mouse. Taken together, these data provide some of the most powerful support for the author's hypothesis.

\section{Age of maturation in gerbils}

In Mongolian gerbils, the age at vaginal opening is bimodally distributed with means of about 16 and 35 days. It has been shown (Clark et al. 1986, Clark \& Galef 1988) that litters of late-maturing females have a highly significantly higher offspring sex ratio than those of early maturing females. The probability that a female matures early is strongly related to her own position in utero: the probability is much lower if she was situated adjacent to one or more male foetuses. And (as noted above) this in turn correlates with her adult testosterone level. Accordingly, the author proposes that the variation of offspring sex ratio with age at maturation in gerbils is mediated by testosterone levels.

\section{Diet in mice}

Rosenfeld et al. (2003) reported that female mice reared on a high-fat diet had a substantially and significantly higher offspring sex ratio than those fed a low-fat diet. The effect was reportedly dependent on the amount of fat consumed (Alexenko et al. 2007). The same group of authors reported that in female mice, the high-fat diet was associated with higher levels of oestradiol (Whyte et al. 2007). These authors further reported that female mice fed diets enriched with $\omega-6$ polyunsaturated fatty acid produced a highly significant excess of female offspring (Fountain et al. 2007). It is established that $\omega-6$ polyunsaturated fatty acid has anti-oestrogenic properties (Menendez et al. 2004).

The author suggests that the high and low offspring sex ratios reported in these two experiments are due respectively to the high and low levels of oestrogenic activity in the dams.

\section{Duration of oestrus in heifers}

Ideta et al. (2007) reported that heifers bearing males had a significantly longer duration of oestrus, on the average, than those bearing females. These authors write: "further, studies are needed to evaluate to what degree maternal hormone levels are related to oestrus duration and sex ratio'. Mondal et al. (2006) reported that oestrus behaviour correlates positively with oestrogen levels in cows. The author suggests that the variation of offspring sex ratio with duration of oestrus is secondary to correlations of both with oestrogen levels.

\section{Oestrogen fertilization medium and mouse embryos}

Zhang et al. (2006) found that mouse embryos incubated in high levels of oestradiol 17- $\beta\left(E_{2}\right)$ had a significantly high sex ratio as compared with controls. This research was prompted by and gives direct support to the author's hypothesis.

\section{Excising sex glands of hamsters}

After the coagulatory glands and/or seminal vesicles were excised bilaterally from male golden hamsters, they sired highly significant excesses of male offspring (Chow et al. 1996). These authors report that the phenomenon is not associated with reduced litter size (and hence is not caused by sex-selective abortion). In male rats, prostatectomy results in stimulation of testicular androgens (Chaudhuri et al. 1991). It seems reasonable to suppose that such a phenomenon may operate across species: so the author suggests that the male excess among the offspring of the experimental golden hamsters was due to their high $\mathrm{T}$ levels.

\section{Heat stress in mice and sperm quality and fertility}

Perez-Crespo et al. (2007) reported that male mice were exposed to heat stress and then mated $6 \mathrm{~h}$ later with unexposed females. These authors noted that heat stress has deleterious effects on sperm quality, and they found that the resulting offspring sex ratio was significantly low. They cited a study reporting analogous findings viz that in red deer, sperm quality of males also correlated positively and significantly with offspring sex ratio (Gomendio et al. 2006). The author has offered an explanation of the latter data (James 2007). The author suggests that this explanation may apply also to the data of Perez-Crespo et al. (2007). The correlation between sperm quality and offspring sex ratio is secondary to correlations of both with paternal testosterone/gonadotrophin ratio. 
Gomendio et al. (2006) also reported a significant positive correlation between the total fertility of red deer and their offspring sex ratio. A similar association has been described in human families. A century ago, the largest European families contained slightly but significantly higher proportion of boys (Schutzenberger 1950, Edwards 1958). This occurred in spite of negative associations between a) sex ratio and b) birth order and paternal age (James 1987). The association between human fertility and sex ratio may also be mediated by paternal $\mathrm{T}$.

\section{6-MBOA in voles}

Berger et al. (1987) experimented with 6-MBOA, a plant derivative which initiates reproduction in field populations of the meadow vole. Experimental animals of both sexes received implants of 6-MBOA and were subsequently mated. Treated animals of both sexes produced significantly more female offspring than untreated controls. Schadler et al. (1988) showed that 6-MBOA provokes excretion of LH in pine voles. In conformity with the author's hypothesis, gonadotrophin selects for female offspring in the meadow vole. Apparently, the selection was pre-zygotic: the authors deny that resorption occurred to any extent.

\section{Parasitic infection in mice}

\section{Heligmosomoides polygyrus}

Ehman \& Scott (2002) found that litters sired by male mice parasitized by this organism had significantly low sex ratios. Parasitic infection of male mammals (including mice) lowers their T levels (Hillgarth \& Wingfield 1997, Barnard et al. 1998). So Ehman \& Scott (2002) suggested that 'parasite-induced hormonal changes may alter the sex ratio of offspring', in confirmation of the author's hypothesis.

\section{Toxoplasma gondii}

As noted above (in section T. gondii infection), Kankova et al. (2007b) reported that experimentally infected female mice produce significantly high offspring sex ratios - just as had been reported by the same group of workers in respect of human beings (Kankova et al. 2007a).

Kankova et al. (2007b) claimed that the observational data on the offspring sex ratio of infected women gives no clue on whether the infection is the cause of the increase in sex ratio, or whether some other factor (e.g. high $\mathrm{T}$ ) may be responsible both for the higher risk of infection and for the higher sex ratio. These workers also claim that their experimental mouse study 'clearly shows that the increased sex ratio is the effect of latent toxoplasmosis'. It is suggested that the argument is not as clear as their wording would imply. The infection may have caused their female mice to secrete high levels of adrenal androgens as a response to the stress of infection and thus ex hypothesi to produce an excess of male pups. Since, males (in contrast with females) characteristically react to stress by a lowering of (testicular) androgens (Christiansen 2004), one might provisionally expect a different sex ratio result in male subjects. It would be interesting to see such data on men and male mice.

\section{Splenial area of rats}

In the rat, the splenium of the corpus callosum is sexually dimorphic, being larger in males. Testosterone injections in females increase the size of their splenium. In accordance with the author's hypothesis, Nunez \& Juraska (1998) found that the offspring sex ratio of females correlates with their splenial area.

\section{Follicular fluid testosterone levels and subsequent sex of bovine embryos}

Grant \& Irwin (2005) reported that they took ova from bovine follicles and fertilized them in vitro. Each sample of follicular fluid was assayed for testosterone. These authors found that the testosterone levels significantly correlated with the sex of the resulting zygotes. These findings were confirmed in a subsequent study (Grant et al. cited in Grant 2007). The testosterone concentrations could be causally responsible for the sexes of the offspring.

\section{Summary}

In some quarters, there is public suspicion of, and antagonism towards, science. Scientists frequently deplore this suspicion and antagonism. Less frequently they deplore their own resistance to scientific evidence - though it is not unknown (Barber 1961). The present hypothesis was adumbrated nearly three decades ago. But deliberate attempts to test it have only recently been initiated. Readers should also read the accompanying editorial (Clark \& Davis 2008) to gain a better perspective of this hypothesis article. As a retired armchair epidemiologist and not qualified to test it experimentally, the author hopes that the foregoing account will stimulate others to test the hypothesis.

\section{Declaration of Interest}

The author declares that there is no conflict of interest that would prejudice the impartiality of this scientific work.

\section{Funding}

This research did not receive any specific grant from any funding agency in the public, commercial or not-for-profit sector.

\section{Acknowledgements}

The author is grateful to Prof Brenda Eskenazi (University of California at Berkeley), Dr N Khanjani (Monash University Australia) and Dr M Zwitter (Ljubljana, Slovenia) for 
responding to requests for data; Prof B S Blumberg (Fox Chase Cancer Center, Philadelphia), Dr J Flegr (Department of Parasitology, Charles University, Prague), the late Dr Anne McLaren DBE, FRS (Cambridge), Prof H Moller (Guys, Kings and St Thomas' School of Medicine), Prof A Pomiankowski (University College London), and Dr E Rajpert-De Meyts (Copenhagen) for help and encouragement. Lastly the author would like to pay tribute to the late Dr A R Jonckheere and the late Prof C A B Smith (both formerly of University College London). They agreed to supervise his $\mathrm{PhD}$ thesis in 1963, and they continued to help him for the rest of their lives, showing generosity far beyond the call of academic duty.

\section{References}

Alexenko AP, Mao J, Ellersieck MR, Davis AM, Whyte JR, Rosenfeld CS \& Roberts RM 2007 The contrasting effects of ad libitum feeding of a diet very high on saturated fats on sex ratio and metabolic hormones in mice. Biology of Reproduction 77 599-604.

Arena JFP \& Smith DW 1978 Sex liability to single structural defects. American Journal of Diseases of Children 132 970-972.

Askling J, Erlandsson G, Kaijser M, Akre O \& Ekbom A 1999 Sickness in pregnancy and sex of child. Lancet 3542053.

Astolfi P, Cuccia M \& Martinetti M 2001 Paternal HLA genotype and offspring sex ratio. Human Biology 73 315-319.

Barber B 1961 Resistance of scientists to scientific discovery. Science 134 596-602.

Barnard CJ, Behnke JM, Gage AR, Brown H \& Smithurst PR 1998 The role of parasite-induced immunodepression, rank and social environment in the modulation of behaviour and hormone concentrations in male laboratory mice (Mus musculus). Proceedings of the Royal Society of London. Series B $\mathbf{2 6 5}$ 693-701.

Beral V \& the Million Women Study Collaborators 2003 Breast cancer and hormone replacement therapy: the Million Women Study. Lancet $362419-427$.

Berger PJ, Negus NC \& Rowsemitt CN 1987 Effect of 6-methoxybenzoxazolinone on sex ratio and breeding performance in Microtus montanus. Biology of Reproduction 36 255-260.

Blumberg BS 2006 The curiosities of hepatitis B virus: prevention, sex ratio and demography. Proceedings of the American Thoracic Society 3 14-20.

Bodmer WF \& Edwards AWF 1960 Natural selection and the sex ratio. Annals of Human Genetics 24 239-244.

Brooks RJ, James WH \& Gray E 1991 Modelling sub-binomial variation in the frequency of sex combinations in litters of pigs. Biometrics 47 403-417.

Cameron EZ \& Linklater WL 2007 Extreme sex ratio variation in relation to change in condition around conception. Biology Letters 3 395-397.

Catalano R, Bruckner T, Marks AR \& Eskenazi B 2006 Exogenous shocks to the human sex ratio: the case of September 11th, 2001 in New York City. Human Reproduction 21 3127-3131.

Chahnazarian A, Blumberg BS \& London WT 1988 Hepatitis B and the sex ratio at birth: a comparative analysis of four populations. Journal of Biosocial Science 20 357-370.

Chang BL, Robbins WA, Wei F, Xun L, Wu G \& Elashoff DA 2006 Boron workers in China: exploring work and lifestyle factors related to boron exposure. American Association of Occupational Health Nurses Journal 54 435-443.

Chaudhuri A, Ghosh D, Chatterjee AK, Biswas NM \& Ghosh PK 1991 Adrenal corticosteroidogenesis after removal of ventral prostate gland. Experientia 47 86-88.

Chow PH, Cheung MPL \& O WS 1996 Increased secondary sex ratios in golden hamster litters sired by males without coagulatory glands and seminal vesicles. Reproduction, Fertility, and Development 8 297-300.

Christiansen K 2004 Behavioural correlates of testosterone. In Testosterone: Action. Deficiency. Substitution Eds E Nieschlag, HM Behre \& S Nieschlag. Cambridge, UK: Cambridge University Press, pp 125-172.
Clark AJL \& Davis JRE 2008 Editorial. Journal of Endocrinology 1981.

Clark MM \& Galef BG 1988 Effects of uterine position on rate of sexual development in female Mongolian gerbils. Physiology and Behavior 42 15-18. Clark MM \& Galef BG 1994 Reply. Nature 367328.

Clark MM, Spencer CA \& Galef BG 1986 Reproductive life history correlates of early and late sexual maturation in Mongolian gerbils (Meriones unguiculatus). Animal Behaviour 34 551-560.

Clark MM, Karpiuk P \& Galef BG 1993 Hormonally mediated inheritance of acquired characteristics in Mongolian gerbils. Nature 364712.

Clutton-Brock TH \& Lason GR 1986 Sex ratio variation in mammals. Quarterly Review of Biology 61 339-374.

Cocco P, Fadda D, Ibba A, Melis M, Tocca MG, Atzeri S, Avataneo G, Meloni M, Monni F \& Flore C 2005 Reproductive outcome in DDT applicators. Environmental Research 98 120-126.

Collins JA, Blake JM \& Crosignani PG 2005 Breast cancer risk with postmenopausal hormonal treatment. Human Reproduction Update 11 545-560.

Cutolo M \& Accardo S 1991 Sex hormones, HLA and rheumatoid arthritis. Clinical and Experimental Rheumatology 9 641-646.

Depue RH, Bernstein L, Ross RK, Judd HL \& Henderson B 1987 Hyperemesis gravidarum in relation to estradiol levels, pregnancy outcome and other maternal factors: a sero-epidemiological study. American Journal of Obstetrics and Gynecology 156 1137-1141.

Dickinson H \& Parker L 1994 Do alcohol and lead change the sex ratio? Journal of Theoretical Biology 169313.

Edmonds C \& Hayward L 1987 Intellectual impairment with diving: a review. Ninth International Symposium on Underwater and Hyperbaric Physiology. Undersea and Hyperbaric Medical Society, Bethesda, Maryland pp 877-886.

Edwards AWF 1958 An analysis of Geissler's data on the human sex ratio. Annals of Human Genetics 23 6-15.

Egeland GM, Sweeney MH, Fingerhut MA, Wille KK, Schnorr TM \& Halperin WE 1994 Total serum testosterone and gonadotropins in workers exposed to dioxins. American Journal of Epidemiology 139 272-281.

Ehman KD \& Scott ME 2002 Female mice mate preferentially with nonparasitized males. Parasitology 125 461-466.

Figa-Talamanca I, Tarquini M \& Lauria L 2003 Is it possible to use sex ratio at birth as indicator of the presence of endocrine disruptors in environmental pollution? (In Italian) Giornale Italiano di Medicina Del Lavoro ed Ergonomia 25(Suppl 3) 52-53.

Flegr J, Hruskova M, Hodny Z, Novotna M \& Hanusova J 2005 Body height, body mass index, waist-hip ratio, fluctuating asymmetry and second to fourth digit ratio in subjects with latent toxoplasmosis. Parasitology 130 621-628.

Fountain ED, Mao J, Whyte JJ, Mueller KE, Ellersieck MR, Will LJ, Roberts RM, Macdonald R \& Rosenfeld CS 2007 Effects of diets enriched in omega-3 and omega-6 polyunsaturated fatty acids on offspring sex ratio and maternal behaviour in mice. Biology of Reproduction (Epub 10.10.07).

Garry VF, Harkins ME, Erickson LL, Long-Simpson LK, Holland SE \& Burroughs BL 2002a Birth defects, season of conception and sex of children born to pesticide applicators living in the Red River Valley of Minnesota, USA. Environmental Health Perspectives 110(Suppl 3) 441-449.

Garry VF, Harkins M, Lyubimov A, Erickson L \& Long L $2002 b$ Reproductive outcomes in the women of Red River Valley of the North. 1. The spouses of pesticide applicators: pregnancy loss, age at menarche and exposure to pesticides. Journal of Toxicology and Environmental Health 65 769-786.

Garry VF, Holland SE, Erickson LL \& Burroughs BL 2003 Male reproductive hormones and thyroid function in pesticide applicators in the Red River Valley of Minnesota. Journal of Toxicology and Environmental Health. Part A 66 965-986.

Gini C 1955 Sulla probabilita che $x$ termini di una serie erratica sieno crescenti (o non decrescenti) ovvero tutti decrescenti (or non crescenti) con applicazioni ai rapporti dei sessi nascite umane in intervalli successivi e alle disposizioni dei sessi nelle fratellanze umane. Metron 17 1-41.

Giusti RM, Iwamoto K \& Hatch EE 1995 Diethylstilbestrol revisited: a review of the long-term health effects. Annals of Internal Medicine 122 778-788.

Gomendio M, Malo AF, Soler AJ, Fernandez-Santos MR, Esteso MC, Garcia AJ, Roldan ER \& Garde J 2006 Male fertility and sex ratio at birth in red deer. Science 314 1445-1447.

Grant V 1994 Maternal dominance and the conception of sons. British Journal of Medical Psychology 67 343-351. 
Grant VJ 2007 Could maternal testosterone levels govern mammalian sex ratio deviations? Journal of Theoretical Biology 246 708-719.

Grant VJ \& France JT 2001 Dominance and testosterone in women. Biological Psychology 58 41-47.

Grant VJ \& Irwin RJ 2005 Follicular fluid steroid levels and subsequent sex of bovine embryos. Journal of Experimental Zoology 303A 1120-1125.

Gundy S, Babosa M, Baki M \& Bodrigi I 2004 Increased predisposition to cancer in brothers and offspring of testicular tumor patients. Pathology Oncology Research 10 197-203.

Gutierrez-Adan A 2001 Influence of glucose on the sex ratio of bovine IVM/IVF embryos cultured in vitro. Reproduction, Fertility, and Development 13 361-365.

Harris JA, Vernon PA \& Boomsma DI 1998 The heritability of testosterone: a study of Dutch adolescent twins and their parents. Behavior Genetics 28 165-171.

Hedricks C \& McClintock MK 1990 Timing of insemination is correlated with the secondary sex ratio of Norway rats. Physiology and Behavior 48 625-632.

Hillgarth N \& Wingfield JC 1997 Parasite-mediated sexual selection: endocrine aspects. In Host-Parasite Evolution Eds DH Clayton \& J Moore. New York: Oxford University Press, pp 78-104.

Hodges LC, Bergerson JS, Hunter DS \& Walker CL 2000 Estrogenic effects of organochlorine pesticides on uterine leiomyoma cells in vitro. Toxicological Sciences 54 355-364.

Hodlova H, Kolbekova P, Skallova A, Lindova J \& Flegr J 2007 Higher perceived dominance in Toxoplasma infected men - new evidence for role of testosterone in toxoplasmosis-associated changes in human behaviour. Neuroendocrinology Letters 28 101-105.

Hsu CD \& Witter FR 1993 Fetal sex and severe hyperemesis gravidarum. International Journal of Gynaecology and Obstetrics 40 63-64.

Hwang SY, Kim W-J, Wee J-J, Choi J-S \& Kim S-K 2004 Panax ginseng improves survival and sperm quality in guinea pigs exposed to $2,3,7,8$ tetrachlorodibenzo- $p$-dioxin. BJU International 94 663-668.

Ideta A, Hayama K, Urakawa M, Jung YG, Lim KT, Lee WY, Song HB \& Aoyagi Y 2007 Relationships among estrus behaviour, superovulatory response and Grade 1 embryo sex ratio in superovulated Holstein heifers. Journal of Reproduction and Development .

Ishihara K, Warita K, Tanida T, Sugawara T, Kitagawa H \& Hoshi N 2007 Does paternal exposure to 2,3,7,8-tetrachlorodibenzo-p-dioxin affect the sex ratio of offspring? Journal of Veterinary Medical Science 69 347-352.

Jacobsen R, Bostofte E, Skakkebaek NE, Hansen J \& Moller H 2000a Offspring sex ratio of subfertile men and men with abnormal sperm characteristics. Human Reproduction 15 2369-2370.

Jacobsen R, Bostofte E, Engholm G, Hansen J, Skakkebaek NE \& Moller H $2000 b$ Fertility and offspring sex ratio of men who develop testicular cancer: a record linkage study. Human Reproduction 15 1958-1961.

James WH 1980 Gonadotrophin and the human secondary sex ratio. BMJ 281 711-712.

James WH 1985a The sex ratio of infants born after hormonal induction of ovulation. British Journal of Obstetrics and Gynaecology 92 299-301.

James WH $1985 b$ The sex ratio of infants born after hormonal induction of ovulation: author's replies. British Journal of Obstetrics and Gynaecology 92 993-996.

James WH 1986 Hormonal control of sex ratio. Journal of Theoretical Biology 118 427-441.

James WH 1987 The human sex ratio. Part 1: a review of the literature. Human Biology 59 721-752.

James WH 1989 Parental hormone levels and mammalian sex ratios at birth. Journal of Theoretical Biology 139 59-67.

James WH 1992 The hypothesized hormonal control of mammalian sex ratio at birth - a second update. Journal of Theoretical Biology 155 121-128.

James WH 1995a Sex ratios of offspring and the causes of placental pathology. Human Reproduction 10 1403-1406.

James WH $1995 b$ Re: total serum testosterone and gonadotropins in workers exposed to dioxins. American Journal of Epidemiology 141 476-477.

James WH 1995c What stabilizes the sex ratio? Annals of Human Genetics 59 243-249.
James WH 1996 Evidence that mammalian sex ratios at birth are partially controlled by parental hormone levels at the time of conception. Journal of Theoretical Biology 180 271-286.

James WH 1997 A potential mechanism for sex ratio variation in mammals. Journal of Theoretical Biology 189 253-255.

James WH 1998a The sex ratio of offspring of people exposed to boron. Reproductive Toxicology 12673

James WH 1998b Hypothesis: one cause of polydactyly. Journal of Theoretical Biology 192 1-2.

James WH 1999 Is transposition of the great arteries a consequence of maternal hormone imbalance? Evidence from the sex ratios of the relatives of probands. Journal of Theoretical Biology 198 301-303.

James WH $2000 a$ Analysing data on the sex ratio of human births by cycle day of conception. Human Reproduction 15 1206-1207.

James WH $2000 b$ The sex ratio of children born to women with dermatoses of pregnancy. British Journal of Dermatology 1431345.

James WH 2000c Are oral clefts a consequence of maternal hormone imbalance? Evidence from the sex ratios of siblings of probands. Teratology 62 342-345.

James WH 2001a The data sources which may help strengthen the epidemiological evidence for the hormonal hypothesis of sex determination in man. Human Reproduction 16 1081-1085.

James WH $2001 b$ Finger length ratios, sexual orientation and offspring sex ratios. Journal of Theoretical Biology 212 273-274.

James WH 2001c The associated offspring sex ratios and cause(s) of hyperemesis gravidarum. Acta Obstetrica et Gynecologica Scandinavica 80 378-379.

James WH 2001d The sex ratio of births associated with placenta praevia. Journal of Obstetrics and Gynaecology 21 160-161.

James WH 2004a Further evidence that mammalian sex ratios at birth are partially controlled by parental hormone levels around the time of conception. Human Reproduction 19 1250-1256.

James WH $2004 b$ possible cause of pyloric stenosis. Birth Defects Research. Part A, Clinical and Molecular Teratology 70 37-39.

James WH 2006a Are there preconceptual determinants of mammalian sex? A response to Boklage (2005) Human Reproduction 21 2486-2490.

James WH $2006 b$ Offspring sex ratios at birth as markers of paternal endocrine disruption. Environmental Research 100 77-85.

James WH 2006c Sex ratios of offspring of patients with breast cancer and other endocrine related cancers. International Journal of Cancer 119 2710-2711.

James WH 2006d Possible constraints on adaptive variation in sex ratio at birth in humans and other primates. Journal of Theoretical Biology 238 383-394.

James WH 2007 Testosterone and male fertility in red deer. Science 316 980-981.

James WH 2008 Further evidence that some male-biased neurodevelopmental disorders are associated with high intrauterine testosterone concentrations. Developmental Medicine and Child Neurology.

Jansen RPS 1984 Endocrine response in the Fallopian tube. Endocrine Reviews 5 525-551.

Jimenez A, Fernandez R, Madrid BN, Moreira PN, Borque C, Pintado B \& Gutierrez AA 2003 Experimental demonstration that pre- and postconceptional mechanisms influence sex ratio in mouse embryos. Molecular Reproduction and Development 66 162-165.

Kankova S, Sulc J, Nouzova K, Fajfrlik K, Frynta D \& Flegr J 2007a Women infected with parasite Toxoplasma have more sons. Naturwissenschaften 94 122-127.

Kankova S, Kodym P, Frynta D, Vavrinova R, Kubena A \& Flegr J 2007 b Influence of latent toxoplasmosis on the secondary sex ratio in mice. Parasitology (In press).

Keulers MJ, Hamilton CJCM, Franx A, Evers JLH \& Bots RSGM 2007 The length of the fertile window is associated with the chance of spontaneously conceiving an ongoing pregnancy in subfertile couples. Human Reproduction 22 1652-1656.

Khanjani N \& Sim MR 2006 Maternal contamination with dichlorodiphenyltrichloroethane and reproductive outcomes in an Australian population. Environmental Research 101 373-379.

Leplow B, Tetzlaff K, Holl D, Zeng L \& Reuter M 2001 Spatial orientation in construction divers - are there associations with diving experience? Archives of Environmental and Occupational Health 74 189-198. 
Lubinsky MS 1997 Classifying sex-biased congenital anomalies. American Journal of Medical Genetics 69 225-228.

Lyster WR 1982 Altered sex ratio in children of divers. Lancet ii 152.

Mandal PK 2005 Dioxin: a review of its environmental effects and its aryl hydrocarbon receptor biology. Journal of Comparative Physiology ' $B$ ' Biochemical, Systematic and Environmental Physiology 175 221-230.

Manning JT 2002 Digit Ratio: A Pointer to Fertility, Behavior and Health., London: Rutgers University Press.

Manning JT, Scutt D, Wilson J \& Lewis-Jones DI 1998 The ratio of 2nd to 4th digit length: a predictor of sperm numbers and concentrations of testosterone, luteinizing hormone and oestrogen. Human Reproduction $\mathbf{1 3}$ 3000-3004.

Manning JT, Martin S, Trivers RL \& Soler M 2002 2nd to 4th digit ratio and offspring sex ratio. Journal of Theoretical Biology 217 93-96.

Martin SA, Harlow SD, Sowers F, Longnecker MP, Garabrant D, Shore DL \& Sandler DP 2002 DDT metabolite and androgens in African American farmers. Epidemiology 13 454-458.

Marx PA, Spira AI, Gettie A, Dailey PJ, Veazey RS, Lackner AA, Mahoney CJ, Miller CJ, Claypool LE, Ho DD et al. 1996 Progesterone implants enhance SIV vaginal transmission and early virus load. National Medicine 2 1084-1089.

Matsumoto AM, Paulsen CA, Hopper BR \& Rebar RW 1983 Human chorionic gonadotropin and testicular function: stimulation of testosterone, testosterone precursors and sperm production despite high estradiol levels. Journal of Clinical Endocrinology and Metabolism 56 720-728.

Mazzur S \& Watson TM 1974 Excess males among siblings of Australia antigen carriers. Nature 250 60-61.

McQueen D, Kent G \& Murrison A 1994 Self-reported and long-term effects of diving and decompression illness in recreational SCUBA divers. British Journal of Sports Medicine 28 101-104.

Menendez JA, Colomer R \& Lupu R 2004 Omega-6 polyunsaturated fatty acid gamma-linolenic acid (18: $3 n-6)$ is a selective estrogen response modulator in human breast cancer cells: gamma-linolenic acid antagonizes estrogen receptor-dependent transcriptional activity, transcriptionally represses estrogen receptor expression and synergistically enhances tamoxifen and ICI 182,780 (Faslodex) efficacy in human breast cancer cells. International Journal of Cancer 109 949-954.

Mocarelli P, Brambilla P, Gerthoux PM, Patterson DG \& Needham LL 1996 Change in sex ratio with exposure to dioxin. Lancet 348409.

Mocarelli P, Gerthoux PM, Ferrari E, Patterson DG, Kieszak SM, Brambilla P, Vincoli N, Signorini S, Tramacere P, Carreri V et al. 2000 Paternal concentrations of dioxin and sex ratio of offspring. Lancet 355 1858-1863.

Moller H 1998 Trends in sex ratio, testicular cancer and male reproductive hazards: are they connected? Acta Pathologica, Microbiologica, et Immunologica Scandinavica 106 232-239.

Mondal M, Rajkhowa C \& Prakash BS 2006 Relationship of estradiol-17 beta, total estrogen and progesterone to estrus behaviour in mithun (Bos frontalis) cows. Hormones and Behavior 49 626-633.

Nunez JL \& Juraska JM 1998 The size of the splenium of the rat corpus callosum: influence of hormones, sex ratios and neonatal cryoanesthesia. Developmental Psychobiology 33 295-303.

Ollier W, Spector T, Silman A, Perry L, Ord J, Thomson W \& Festenstein H 1989 Are certain HLA haplotypes responsible for low testosterone levels in males? Disease Markers 7 139-143.

Olsson H 1984 Epidemiological studies in malignant lymphoma with special reference to occupational exposure to organic solvents and to reproductive factors. Doctoral Dissertation Presented to the University of Lund.

Olsson H \& Brandt L 1982 Sex ratio in offspring of patients with nonHodgkin lymphoma. New England Journal of Medicine 306367

Orban JE, Stanley JS, Schwemberger JG \& Remmers JC 1994 Dioxins and dibenzofurans in adipose tissue of the general USA population and selected subpopulations. American Journal of Public Health 84 439-445.

Oster E 2005 Hepatitis B and the case of the missing women. Journal of Political Economy 113 1163-1216.

Padron RS, Wischusen J, Hudson B, Burger HG \& De Kretser DM 1980 Prolonged biphasic response of plasma testosterone to single intramuscular injections of human chorionic gonadotropin. Journal of Clinical Endocrinology and Metabolism 50 1100-1104.
Paltieli Y, Eibschitz I, Ziskind G, Ohel G, Silbermann M \& Weichselbaum A 2000 High progesterone levels and ciliary dysfunction - a possible cause of ectopic pregnancy. Journal of Assisted Reproduction and Genetics 17 103-106.

Paul A \& Kuester J 1987 Sex ratio adjustment in a seasonally breeding primate species: evidence from the Barbary macaque population at Affenberg Salem. Ethology 74 117-132.

Perez-Crespo M, Pintado B \& Gutierrez-Adan A 2007 Scrotal heat stress effects on sperm viability, sperm DNA integrity and the offspring sex ratio in mice. Molecular Reproduction and Development

Perret M 1986 Social influences on oestrous cycle length and plasma progesterone concentrations in the female lesser mouse lemur (Microcebus murinus). Journal of Reproduction and Fertility 77 300-311.

Perret M 1990 Influence of social factors on sex ratio at birth, maternal investment and young survival in a prosimian primate. Behavioral Ecology and Sociobiology 27 447-454.

Perret M 1996 Manipulation of sex ratio at birth by urinary cues in a prosimian primate. Behavioral Ecology and Sociobiology 38 259-266.

Perret M \& Colas S 1997 Manipulation of sex ratio at birth and maternal investment in female mouse lemurs (Microcebus murinus, Primates). Applied Animal Behaviour Science 51 275-283.

Perry MJ, Ouyang F, Korrick SA, Venners SA, Chen C, Xu X, Lasley BL \& Wang X 2006 A prospective study of serum DDT and progesterone and estrogen levels across the menstrual cycle in nulliparous women of reproductive age. American Journal of Epidemiology 164 1056-1064.

Petersen PM, Skakkebaek NE, Vistisen K, Rorth M \& Giwercman A 1999 Semen quality and reproductive hormones in men with testicular cancer. Journal of Clinical Oncology 17 941-947.

Piazze J, Nigro G, Mazzocco M, Marchiani E, Brancato V, Anceschi MM \& Cosmi EV 1999 The effect of primary cytomegalovirus infection on fetal lung maturity indices. Early Human Development 54 137-144.

Potashnik G \& Yanai-Inbar I 1987 Dibromochloropropane (DBCP): an 8 -year re-evaluation of testicular function and reproductive performance. Fertility and Sterility 47 317-323.

Pratt NC, Huck UW \& Lisk RD 1987 Offspring sex ratio in hamsters is correlated with vaginal $\mathrm{pH}$ at certain times of mating. Behavioral and Neural Biology 48 310-316.

Rhouma KB, Tebourbi O, Krichah R \& Sakly M 2001 Reproductive toxicity of DDT in adult male rats. Human and Experimental Toxicology 20 393-397.

Robbins WA, Wei F, Elashoff DA, Wu G, Xun L \& Jia J 2007 Y:X sperm ratio in boron-exposed men. Journal of Andrology .

Rockert HOE 1977 Changes in the vascular bed in testes of rats exposed to air at 6 atmospheres absolute pressure. IRCS Journal of Medical Science 5107.

Rockert HOE \& Haglid K 1983 Reversible changes in the rate of DNA synthesis in the testes of rats after daily exposure to a hyperbaric environment of air. IRCS Journal of Medical Science 11531.

Rockert HOE, Damber J-E \& Janson PO 1978 Testicular blood flow and plasma testosterone concentrations in anesthetized rats previously exposed to air at 6 ATA. Undersea Biomedical Research 5 355-361.

Rosenfeld CS, Grimm KM, Livingston KA, Brokman AM, Lamberson WE \& Roberts RM 2003 Striking variation in the sex ratio of pups born to mice according to whether maternal diet is high in fat or carbohydrate. PNAS $1004628-4632$.

Ross JAS, Macdiarmid JI, Osman LM, Watt SJ, Godden DJ \& Lawson A 2007 Health status of professional divers and offshore oil industry workers. Occupational Medicine 57 254-261.

Sas M \& Szollosi J 1980 The sex ratio of children of fathers with spermatic disorders following hormone therapy (in Hungarian). Orvosi Hetilap 121 2807-2808.

Schadler MH, Butterstein GM, Faulkner BJ, Rice SC \& Weisinger LA 1988 The plant metabolite 6-methoxybenzoxazolinone stimulates an increase in secretion of FSH and size of reproductive organs in Microtus pinetorum. Biology of Reproduction 38 817-820.

Schiphorst LEM, Collins WP \& Royston JP 1985 An estrogen test to determine the times of potential fertility in women. Fertility and Sterility 44 328-334.

Schutzenberger MP 1950 Nouvelles recherches sur la distribution du sexe a la naissance. La Semaine des Hopitaux 26 4458-4465. 
Shields MD, O’Hare B, Nelson J, Stewart MC \& Coyle P 2002 Maternal cytomegalovirus seropositivity. BMJ 325335.

Short RV 2006 New ways of preventing HIV infection: thinking simply, simply thinking. Philosophical Transactions of the Royal Society of London. Series B: Biological Sciences 361 811-820.

Simonsen CR, Roge R, Christiansen V, Larsen T \& Bonde JP 2006 Effects of paternal blood lead levels on offspring sex ratio. Reproductive Toxicology 22 3-4.

Smith SM, Baskin GB \& Marx PA 2000 Estrogen protects against vaginal transmission of simian immunodeficiency virus. Journal of Infectious Diseases $180708-715$

Speir E, Yu ZX, Takeda K, Ferrans VJ \& Cannon RO 2000 Antioxidant effect of estrogen on cytomegalovirus-induced gene expression in coronary artery smooth cells. Circulation 102 2990-2996.

Trivers RL \& Willard DE 1973 Natural selection of parental ability to vary the sex ratio of offspring. Science 179 90-91.

Vandenbergh JG \& Huggett CL 1994 Mother's prior intrauterine position affects the sex ratio of her offspring in house mice. PNAS 91 11055-11059.

Verme LJ \& Ozoga JJ 1981 Sex ratio of white-tailed deer and the estrus cycle. Journal of Wildlife Management 45 710-715.

Whorton D, Krauss RM, Marshall S \& Milby TH 1977 Infertility in male pesticide workers. Lancet ii 1259-1261.

Whorton D, Milby TH, Krauss RM \& Stubbs HA 1979 Testicular function in DBCP exposed workers. Journal of Occupational Medicine 21 161-166.
Whyte JJ, Alexenko AP, Davis AM, Ellersieck MR, Fountain ED \& Rosenfeld CS 2007 Maternal diet composition alters serum steroid and free fatty acid concentrations and vaginal $\mathrm{pH}$ in mice. Journal of Endocrinology 192 75-81.

Wise LA, Palmer JR, Hatch EE, Troisi R, Titus EL, Herbst AL et al. 2007 Secondary sex ratio among women exposed to diethylstilbestrol in utero. Environmental Health Perspectives 115 1314-1319.

Yuan JM, Ross RK, Stanczyk FZ, Govindarajan S, Gao YT, Henderson BE \& Yu MC 1995 A cohort study of serum testosterone and hepatocellular carcinoma in Shanghai, China. International Journal of Cancer 63 491-493.

Zhang L, Du WH, Chen H, Zhao JH, Pei J \& Lin XK 2006 Impact of reproductive hormones on mouse embryo sexes. Fen $\mathrm{Zi} \mathrm{Xi} \mathrm{Bao} \mathrm{Sheng} W u$ Хие Bao 39 573-577.

Received in final form 31 October 2007

Accepted 6 November 2007

Made available online as an Accepted Preprint

6 November 2007 